\title{
El lenguaje de las imágenes: un análisis pre-iconográfico de la cerámica precolombina del Carchi
}

Gabriela López S.

\section{Resumen}

El PRESENTE ARTículo FORMA PARTE dE UN ANÁlisis PRE-ICONOGRÁFICO REALIZAdo SOBRE UN GRUPO DE PIEZAS

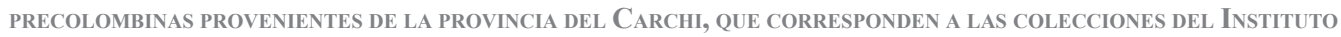
Nacional de Patrimonio Cultural y del Banco Central del Ecuador.

Aunque las 444 piezas analizadas Carecen de CONTEXTo arqueOlógico, el trabajo de INTERPRETACión SE REALIZÓ DESDE UN ENFOQUE ICONOGRÁFICO. SE ANALIZÓ LAS IMÁGENES COMO MENSAJES CODIFICADOS, IDENTIFICANDO FENÓMENOS DE RECURRENCIA Y PONIÉNDOLOS EN RELACIÓN A ESTUDIOS ARQUEOLÓGICOS Y REFERENCIAS ETNOHISTÓRICAS EXISTENTES EN LA ZONA. LOS RESULTADOS HAN PERMITIDO CONTRIBUIR SOBRE TODO CON EL TEMA DE LA CLASIFICACIÓN de las decoraciones cerámicas dentro de las Fases Capulí, Piartal y Tuza, tema sobre el Cual se ha PUESTO ESPECIAL INTERÉS DENTRO DE LAS INVESTIGACIONES LLEVADAS A CABO EN ESTA ZONA, DADA LA NECESIDAD DE EXPLICAR LA FORMA DE ORGANIZACIÓN SOCIAL Y JERARQUIZACIÓN DE ESTOS PUEBLOS.

Palabras clave: Iconografía - Capulí - Piartal - Tuza - arqueología Carchi.

\section{AbTract}

THIS ARTICLE IS PART OF A PRE-ICONOGRAPHIC ANALYSIS PERFORM UPON A GROUP OF PRE-COLUMBIAN PIECES THAT COME From the province of CARChi, CORREsponding to THE Collections of the National Institute of Cultural Heritage and the Central Bank of Ecuador.

EVEN THOUGH THE 444 ANALYZED PIECES DON'T HAVE AN ARCHAEOLOGICAL CONTEXT, THE INTERPRETIVE WORK WAS EXECUTED WITH AN ICONOGRAPHIC FOCUS. THE IMAgES WERE ANALYZED AS CODIFIED MESSAGES, IDENTIFYING RECURRENT PHENOMENA AND CONTRASTING THESE WITH ARCHAEOLOGICAL STUDIES AND ETHNOHISTORIC REFERENCES

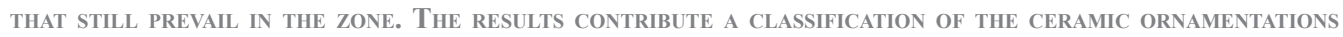
inside the Capulí, Piartal and Tuza phases, a subject of great interest in the investigations done in this AREA BECAUSE OF THE REQUIREMENT OF EXPLAINING THE SOCIAL ORGANIZATION AND THE HIERARCHIZATION OF THESE VILLAGES.

Key words: Iconography - Capulí - Piartal - TuZa - Archaeology - Carchi.

1 Este artículo es parte de la disertación para obtener al título de Antropóloga con mención en Arqueología, PUCE, 2012. Investigadora del proyecto Estudio etnoarqueológico de técnicas ancestrales de producción cerámica y diseños de referentes identitarios, cantón Patate, provincia de Tungurahua. garabyta_16@hotmail.com 


\section{Introducción}

$\mathrm{E}$ 1 desarrollo de la arqueología durante los últimos años ha entrado en una etapa de reevaluación, debido a los grandes procesos de cambio y transformación del pensamiento social y filosófico, razón por la cual se ha nutrido de diferentes perspectivas teóricas, permitiendo generar herramientas de diversa naturaleza, para el estudio y análisis del material cultural.

Este campo ha empezado a tomar importancia sobre todo desde el desarrollo de lo que se conoce como Arqueología Cognitiva. Dicha arqueología plantea la necesidad de llegar a la mente de las personas porque mediante ésta los seres humanos interpretan su realidad, dependiendo de sus sentidos y experiencias pasadas, los mismos que se encuentran inmersos dentro de lo que se conoce como mapa cognitivo. Un grupo de gente que comparte un mismo mundo, tiene mapas cognitivos similares que guían su comportamiento hacia la base material (Renfrew, 1998). El concepto manejado a través de la idea de mapa cognitivo se vuelve indiscutible a la hora de definir la cultura que, asociada a un sistema compartido de símbolos, valores, significados y creencias, se convierte en el estado central para cualquier forma de interpretación arqueológica (Pearson, 2002).

El mundo arqueológico comienza así a ser entendido como un mundo cultural dividido en dos categorías: material y simbólico, no se puede encontrar nada cultural que no sea simbólico. Los seres humanos son vistos, desde este enfoque, como orientadores de su mundo y sus pensamientos, que son expresados en la producción material, y con ello a los símbolos, como características mentales que los actores sociales crean, usan y manipulan para remodelar el mundo en el que viven (Robb, 1998; Pearson, 2002).

En este sentido, la Arqueología Cognitiva, plantea la posibilidad de una investigación en base al supuesto de la existencia de un proceso mental universal, que se puede develar de las experiencias artísticas (Preucel, 2006). Es en este punto que se busca encajar el estudio propuesto, vinculado con un tipo de cerámica, proveniente del registro arqueológico de la actual provincia del Carchi, caracterizada por presentar decoración en base a un sinnúmero de diseños (antropomorfos, zoomorfos, geométricos).

Considerando que el desarrollo de la Arqueología Cognitiva, permite un tipo de acercamiento para el análisis de la materia cultural, no sólo en base a descripciones, ordenamientos, secuencias cronológicas y tipologías, sino poniendo en primer plano, por ejemplo, las representaciones iconográficas y buscando interpretarlas mediante propuestas metodológicas derivadas de otras ciencias, se ha optado por recurrir, en nuestro caso, a los planteamientos de la semiótica, ciencia encargada de los símbolos, las leyes que los gobiernan y las formas de representación que los seres humanos usan para transmitir sus emociones, ideas y experiencias vividas (Castañeiras, 1998; Preucel, 2006; Saussure, 2005).

La semiótica es una ciencia de la cultura y de las convenciones sociales, por lo tanto, permite el estudio de la misma como un proceso de comunicación. Esto es posible, debido a que los seres humanos admiten el uso de códigos para los actos comunicativos (Castañeiras, 1998; Eco, 1994). La creación de códigos sirve para limitar y clasificar los modelos comunicativos que varían por la acción de la ideología, "una determinada manera de usar un lenguaje se identifica con una determinada manera de pensar de la sociedad" (Eco, 1994: 176).

En la comunicación visual, las imágenes se convierten en signos y referentes de la realidad (Castañeiras, 1998). Eco (1994) para explicar la semiótica en el mensaje visual, utiliza el término "signo icónico". Para él los signos icónicos son aquellos que seleccionan los aspectos fundamentales del objeto a través de códigos de reconocimiento, éstos pueden poseer las propiedades ópticas, ontológicas o convencionalizadas del objeto a representar, que como ya habíamos mencionado, se basan en los preceptos de una convención cultural. 
La semiótica y con ella el concepto de signo icónico, se presenta entonces, como la base teórica para analizar las imágenes presentes en nuestro material cerámico. Éstas son entendidas como códigos dentro de un modelo comunicativo que está enteramente relacionado con una cultura y por lo tanto, responde a una ideología en específico.

Hablar de un análisis iconográfico, entendiendo la iconografía como cualquier tipo de manifestación de tipo figurativo, que parte del supuesto en que las imágenes adquieren un valor y un significado (Castañeiras, 1998), y tratar mediante éste de alcanzar una interpretación de los símbolos y vincularlos con el aspecto ideológico de una sociedad, es una tarea muy complicada, sobre todo porque si no se maneja un método científico adecuado estamos propensos a caer en especulaciones, sin embargo, esta aproximación se hace necesaria en la medida en que las imágenes, signos y símbolos son características intrínsecas de la existencia humana.

En este trabajo se presenta un análisis pre-iconográfico, es decir, el primer nivel, de los tres niveles propuestos por Panofsky, precursor en el estudio iconográfico, para el proceso de interpretación de las artes visuales. Una descripción pre-iconográfica es de naturaleza elemental, se la consigue mediante la identificación de formas visibles, en base a objetos que se conocen por la experiencia práctica; su estudio se concentra de manera específica en las formas y las leyes internas que determinan su configuración. Para cualquier nivel de interpretación, es necesario conocer en términos generales, el contexto cultural de los objetos que se van a analizar (Panofsky, 1970: 37-39).

Es así que el siguiente apartado recopila esta información cultural del área de dónde provienen las piezas como paso previo al análisis de las imágenes, que persigue como objetivo obtener una idea clara, global y organizada de la iconografía presente en el material cerámico. Si asumimos que las imágenes constituyen formas simbólicas, es posible que detrás de ellas se encuentre un sistema para definir el mundo y las cosas que se encuentran dentro de él.

\section{Características geográficas y culturales de la región del Carchi}

La actual provincia del Carchi se encuentra en el extremo norte de la sierra ecuatoriana, limitando al Sur con la provincia de Imbabura, al Este con la provincia de Sucumbíos, al Oeste con la provincia de Esmeraldas y al Norte con los ríos San Juan y Carchi, que lo separan del vecino país Colombia.

Uno de los aspectos más relevantes en cuanto a su ubicación, es la presencia de la hoya del Carchi y la hoya del Chota, que han formado una especie de escalera geográfica con una variedad de pisos altitudinales, entre los cuales tenemos la zona fría que comprende páramos extensos y áreas montañosas, favorables para el hábitat de especies como los osos, pumas, dantas, tigrillos, venados, lobos, conejos, sachacuyes, ardillas y aves. La zona templada, caracterizada por la presencia de árboles de nogal, cedro, higuerón, guabo, limoncillo, y por la existencia de minas de oro, plata, antrasita y mármol. Y la zona cálida que comprende los valles, en donde es posible el cultivo de productos subtropicales (Echeverría, 2004).

En cuanto al factor cultural, gracias a las fuentes etnohistóricas (Cieza de León, 1984; Echeverría, 2004; Grijalva, 1988; Landázuri, 1995; Martínez, 1977), se sabe que los grupos asentados en esta región fueron conocidos como "Pastos", sin embargo, el nombre kichwa utilizado por los Incas para designarlos, fue "Quillacingas" (nariz de luna), debido a que sus caciques llevaban narigueras de oro o cobre en forma de media luna (Grijalva, 1988). La región ocupada se extendía desde el norte de Ecuador, hasta el sur de Colombia.

Lo característico de estos grupos son sus casas redondas conocidas como bohíos, éstos fueron hechos por murallas de tierra dispuestas en estructuras circulares que se hallan interrumpidas por una sola entrada. Constituían una sola habitación grande que contenía diferentes espacios organizados para el fogón, camas, alacena y sitios para almacenar agua y chicha. Además se acostumbraba enterrar a los muertos al interior de las mismas, acompañados de alimentos, herramientas o armas. 
De acuerdo a las crónicas, los Pastos utilizaban para vestir unas mantas largas que les cubría desde el pecho hasta las rodillas, y una serie de adornos que debieron responder según el sexo, la ocasión y la categoría, entre los cuales se encuentran las medias lunas o narigueras, aretes, sonajas y cascabeles.

Políticamente, formaban agrupaciones organizadas por cacicazgos, que se refiere a entidades poderosas representadas por un cacique, que entre otras cosas controlaba las actividades económicas. La actividad que experimentó mayor progreso fue la agricultura, esto es evidenciado en la existencia de terrazas, camellones, acequias y tolas. El desarrollo agrícola contribuyó con el desenvolvimiento de sistemas de intercambio basados no sólo en productos de consumo, sino también en bienes de prestigio.

Con respecto al material arqueológico recuperado en esta zona, se han encontrado, asociados a los pueblos descritos en los datos etnohistóricos, vasijas, tumbas, petroglifos, objetos metálicos. La mayoría de los estudios han intentado recrear el panorama del material cerámico buscando llegar a un tipo de organización para establecer cronologías, de los cuáles fueron relevantes los trabajos de Alice Francisco (1969) para Ecuador y de María Victoria Uribe (1977-1978) para Colombia. Las dos propuestas determinan la secuencia de tres estilos en cuanto a forma y decoración: Capulí, Piartal y Tuza. Capulí caracterizado por el uso de diseños en engobe rojo y por la representación de figuras modeladas. Piartal, en cambio relacionado con la introducción de un nuevo color en la arcilla, la presencia de un jarro alto de cuello largo (botijuela) y el aparecimiento de una especie de silbatos pintados y modelados en forma de conchas marinas, que también se encuentran en Tuza, fase que además se identifica por la presencia de un jarro alto de gran abertura que reemplaza a las botijuelas. Uribe considera que entre Piartal y Tuza existe una tradición cultural diferente de Capulí.

Las últimas investigaciones presentan la posibilidad de una contemporaneidad entre estos tres estilos, ya que la información arqueológica indica que los tres se sobreponen tanto en tiempo como en espacio, lo cual crea la posibilidad de que dos o más etnias (Pastos y Quillacingas, por ejemplo) compartan los mismos rasgos estilísticos y que la diferencia de los complejos cerámicos pueda ser explicada bajo el modelo de una sociedad jerarquizada (Cárdenas, 1995; 1996).

Sobre iconografía, ha habido un acercamiento con respecto al análisis del material cerámico, petroglifos y objetos de metal, que ha permitido determinar: la existencia de una connotación simbólica en los caracoles u ocarinas, la importancia en la representación de la figura del mono, la forma geométrica hasta en las representaciones humanas y de fauna, el manejo de colores positivos y negativos, el juego de luces y sombras, y el uso del color rojo para resaltar figuras; particularidades que debieron seguir propósitos específicos posiblemente relacionados con un sistema religioso, tradicional y de creencias, y con concepciones del universo (Bray, 1998; Karadimas, 2000; Molestina, 1998; Schávelzon, 2006; Valarezo, 2010).

\section{Desarrollo metodológico: el tratamiento de las imágenes del corpus cerámico}

Como punto de partida se definió el corpus a investigar tomando en cuenta los siguientes planteamientos: se debe definir un corpus con una colección finita de materiales (piezas cerámicas correspondientes a las colecciones del Instituto Nacional de Patrimonio Cultural y del Museo del Banco Central del Ecuador), éste debe ser bastante extenso para lograr que sus elementos saturen un sistema de semejanzas y diferencias (444 piezas), y debe ser homogéneo en cuanto a su sustancia y limitado en el tiempo (piezas cerámicas precolombinas provenientes de la provincia del Carchi) (Barthes et al., 1972).

En cuanto a los diseños como tales, éstos fueron abordados desde un punto de vista gramatical, mediante el cual, se buscó ordenarlos, clasificarlos y leerlos de cierta forma, para obtener ideas generales de cómo se conjugan en sus diversas representaciones. La clasificación de las imágenes se hizo a partir de la noción de signos icónicos, es decir, tomando en cuenta las relaciones entre los símbolos gráficos y los modelos perceptivos que se construyen a partir del 
conocimiento de un objeto (Eco, 1994). Cada figura fue interpretada de acuerdo al elemento con el que más claramente se asociaba en base a nuestra experiencia práctica: líneas, figuras geométricas, figuras zoomorfas, figuras antropomorfas, etc.

Para la consecución de este propósito, las piezas cerámicas fueron revisadas una por una, fotografiadas desde varias perspectivas y documentadas con sus atributos generales en fichas que permitieron el manejo de la información. Con respecto a las imágenes, éstas fueron ordenadas en tres categorías: una que las clasifica de manera general, en donde se tomaron en cuenta los atributos que permitían unir unas figuras con otras. Otra que las clasifica de manera específica, es decir, considerando los atributos que dentro de un mismo grupo las hacen diferentes, y la última que serviría para determinar características inter-específicas, considerando todas las variaciones posibles de una misma figura.

A cada clasificación se le asignó un código consistente en letras alfabéticas combinadas con números de la siguiente manera: las letras en forma ascendente para la clasificación general, esta letra seguida de un número secuencial para las divisiones dentro de cada categoría, y para las subdivisiones, los códigos anteriores más un punto, seguido de otro número secuencial. Por ejemplo: A Figuras con apariencia lineal - A1 Líneas simples - A1.1 Línea recta - A1.1.1: Lineas rectas paralelas de igual tamaño. La clasificación detallada se presenta en el anexo.

\section{Resultados del análisis pre-iconográfico}

Después de clasificar y ordenar cada una de las imágenes presentes en las decoraciones de las piezas cerámicas, las hemos podido simplificar en siete grupos generales: A figuras con apariencia lineal, B figuras con apariencia geométrica, C figuras con apariencia de sol, D figuras con apariencia zoomorfa, E figuras con apariencia antropomorfa y E figuras con otras formas; cada uno de estos grupos con sus respectivas subdivisiones han sido sometidos a correlaciones estadísticas, permitiéndonos proponer que los diseños del material analizado, están caracterizados, en su mayoría, por el uso de figuras lineales y geométricas como lo demuestra el siguiente gráfico.

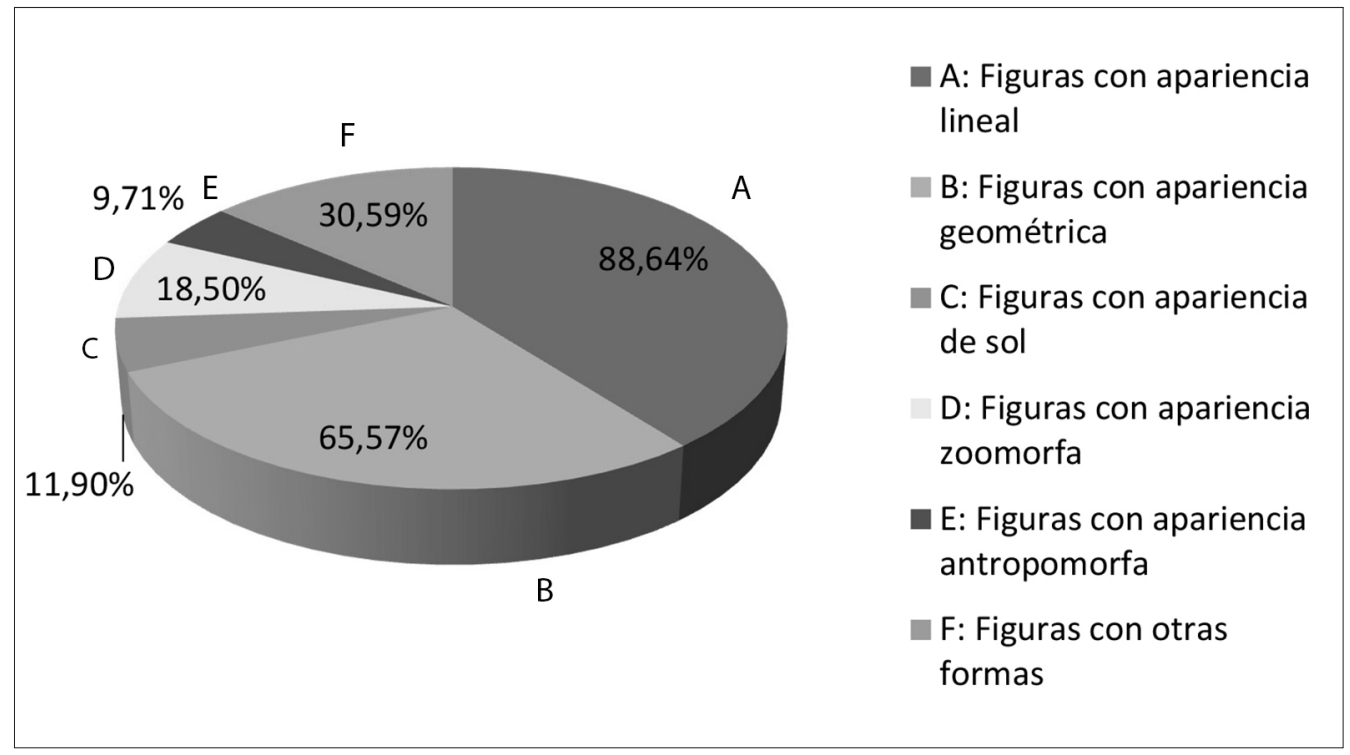

Gráfico 1. Frecuencia del tipo de figuras usadas en los diseños de las piezas CERÁMICAS. 
Los datos estadísticos referentes a las figuras definidas dentro de la clasificación interespecífica de cada grupo, se han puesto en relación a la manera como se encuentran representadas dentro de los estilos Capulí, Piartal y Tuza, que como lo habíamos mencionado en líneas anteriores, están asociados a los resultados de los análisis cerámicos emprendidos en la región. A continuación se presentan las particularidades más relevantes.

A1.1.2
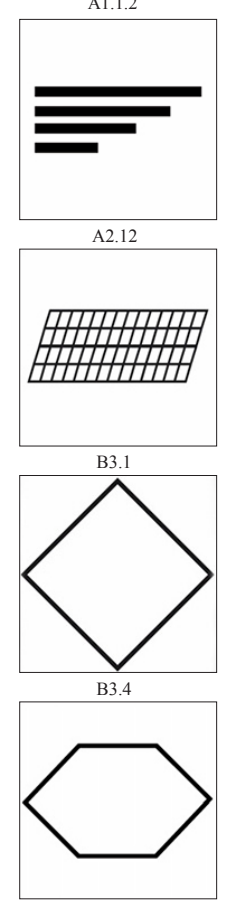

B5.1

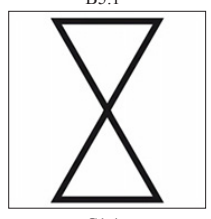

$\mathrm{C} 1.1$
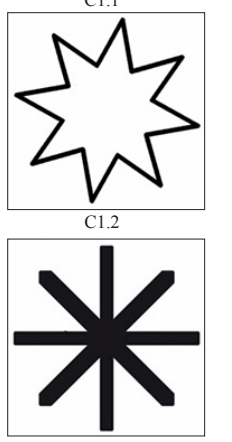

Dentro de las figuras con apariencia lineal, por ejemplo, las líneas simples de tipo A1.1.2, verticales o inclinadas, parecen ser típicas del estilo Piartal, sobre todo en el tipo de decoración al exterior de las compoteras.

Las líneas combinadas de tipo A2.12 han sido las más frecuentemente utilizadas dentro del subgrupo, y están presentes en los tres estilos, aunque con cierta diferenciación en el estilo Tuza, en donde se usa el reticulado para cubrir por completo un panel$^{2}$, o para extender el diseño alrededor de la pieza.

Para el grupo de figuras con apariencia geométrica, las que presentan mayor variabilidad y frecuencia de uso son las figuras con forma triangular. En Piartal, es interesante ver la combinación de unas formas triangulares con otras, generalmente para adornar el exterior de las compoteras.

De las figuras con forma de rombo resaltan las de tipo B3.1 y B3.4 características del estilo Capulí, en donde se adorna el exterior de las piezas con un rombo de tipo B3.4 pintado con líneas más gruesas, y que contiene en su interior un rombo de tipo B3.1 que puede presentarse de cuatro formas: sin ningún relleno, relleno de líneas entrecruzadas, con pequeños puntos que siguen el contorno del mismo y dividido en cuatro partes con puntos contorneando las líneas.

De las figuras con formas especiales, se destaca la de tipo B5.1, que tiene su uso más generalizado en el estilo Tuza, en donde podemos encontrarla representada en el centro de la pieza y asociada a líneas espirales, como ha sucedido también para el estilo Piartal.

Referente al grupo de figuras con apariencia de sol, se ha podido constatar formas de representación que van desde, lo que se podría llamar más simple, hasta lo más complejo. Los soles de tipo C1.1 son propios de Piartal y Tuza. En Piartal es típico que se forme a partir de la representación de otras figuras (triángulos y líneas paralelas) usando como centro la base de las compoteras. Los soles de tipo C1.2 son más comúnmente encontrados en la fase Piartal y en algunos casos están asociados con figuras zoomorfas. El sol con forma rectangular se presenta como un diseño típico de la fase Tuza. Se lo puede encontrar al interior de las compoteras ocupando el centro de las mismas y rodeado por una serie de diseños.

El grupo de figuras con apariencia zoomorfa se relacionan con el uso de dos técnicas: esculpido y pintado. Dentro de esta clasificación son más recurrentes las figuras con apariencia de mono, ave, felino y caracol. De las figuras con forma de mono, en Piartal, se las encuentra representadas formando una línea alrededor de un objeto central, y en Tuza, las encontramos ocupando dos paneles, cuando el diseño se ha dividido en cuatro partes, o modelados, en el borde de una vasija. En las ocarinas tanto Piartal como Tuza, los monos están modelados en uno de los extremos de las mismas.

En cuanto a las figuras con forma de ave, se trata del grupo que más variación muestra, y son características del estilo Piartal y Tuza. Se encuentran

2 Se entiende como panel la división que guarda un diseño para representar el conjunto de figuras que lo componen. Por ejemplo, se pueden usar líneas para dividir los diseños en dos, tres o cuatro partes. Si existen líneas que dividen el diseño en cuatro partes, la primera parte y la tercera presentarán las mismas figuras, mientras que la segunda parte y la cuarta presentarán figuras diferentes, es decir, las representaciones se corresponden unas con otras, dependiendo del número de divisiones. 
representadas al interior de las compoteras de dos formas: frente con frente, con o sin división de paneles, o formando líneas alrededor de una figura central.

Respecto a las figuras con forma de felino, las que se presentan modeladas, se corresponden con los estilos Capulí y Piartal, y se caracterizan por poseer una cola ancha y larga. Las demás figuras aparecen en el estilo Tuza y se representan frente con frente ocupando paneles, formando una línea alrededor de la pieza o adornando las ocarinas.

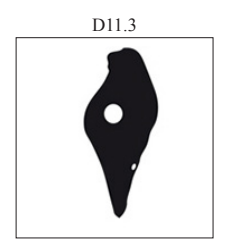

E1.14

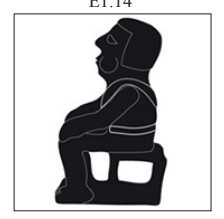

E2.5

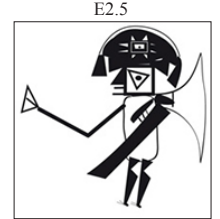

De las figuras con forma de caracol (ocarinas), las de tipo D11.3 tienen rasgos distintivos, en la medida en que todas presentan una figura modelada en uno de sus extremos, sea de monos, aves o figuras antropomorfas, y los diseños que adornan sus cuerpos se forman a partir de líneas incisas.

En base al grupo de figuras con apariencia antropomorfa, dentro de la primera clasificación (figuras antropomorfas que no portan ningún objeto), encontramos que la mayoría de ejemplares son modelados y pertenecen al estilo Capulí. Se distinguen entre ellos por los diseños que adornan sus cuerpos, y por la posición física en la que han sido modelados.

La segunda clasificación de las figuras antropomorfas, correspondiente a los personajes que se han asociado a la posesión de algún objeto, la mayoría se relacionan al estilo Tuza. Comúnmente estos personajes se encuentran representados en parejas, ocupando dos paneles cuando el diseño ha sido dividido en cuatro partes. Existe una excepción y es la figura E2.5, que es la única que se presenta sola y es peculiar el adorno que lleva en su cabeza, de un sol con forma rectangular.

Dentro del grupo de figuras denominadas con otras formas, las figuras con forma de escalera son interesantes, en la medida en que se encuentran presentes en los tres estilos. En Tuza es más común y se las puede encontrar contenidas en un rectángulo dividido en dos partes, y asociadas con líneas espirales, con el sol de apariencia rectangular y con rectángulos que contienen líneas paralelas horizontales.

\section{Una aproximación al lenguaje de las imágenes}

Tras haber distinguido las características específicas de cómo se han presentado cada una de las imágenes de nuestro cuerpo cerámico, fue posible inferir, además, atributos más concretos, composiciones entre figuras, que nos permitan acercarnos a un primer plano de significación de estas imágenes, poniéndolas en relación a los datos recogidos de la historia cultural del área y a otras investigaciones que tratan sobre contenidos iconográficos.

Se ha planteado ya, que las piezas generalmente se componen por diseños lineales y geométricos, en la mayoría de los casos, en donde hay líneas, hay también figuras geométricas, sobre todo en las piezas Capulí y Piartal, en las cuales estos dos tipos de figuras se intercalan con cierto orden y regularidad (por ejemplo se encuentran líneas paralelas verticales, seguidas de rombos, cuadrados o triángulos que se extienden alrededor de la pieza repitiendo esta constante) cubriendo el borde, cuerpo o pedestal de las vasijas.

Respecto a las figuras geométricas, la figura con mayor frecuencia de uso y con más variabilidad de formas es el triángulo. En base a nuestra experiencia práctica sabemos que uniendo triángulos se pueden obtener cuadrados, rectángulos y rombos, por cuanto es posible que, bajo esta premisa, existan nociones de divisiones de elementos en partes iguales, que entre otras cosas puede estar haciendo referencia a la relación de elementos complementarios. Se ha encontrado por ejemplo, un rectángulo dividido en dos partes, uno de los espacios ha sido ocupado por un motivo con forma de escalera, y el otro, por un pequeño rectángulo con una línea en el centro (figura 1). Es decir, la relación en este caso, incluso definida por el contraste de colores, estaría dada por la escalera y por esta forma de representación del rectángulo, cuyas características han sido identificadas en la figura del sol con forma rectangular (solo que en 
éste se usa también dos o más líneas al interior), lo que nos lleva a pensar que tal vez se intente representar el mismo elemento pero simplificado.
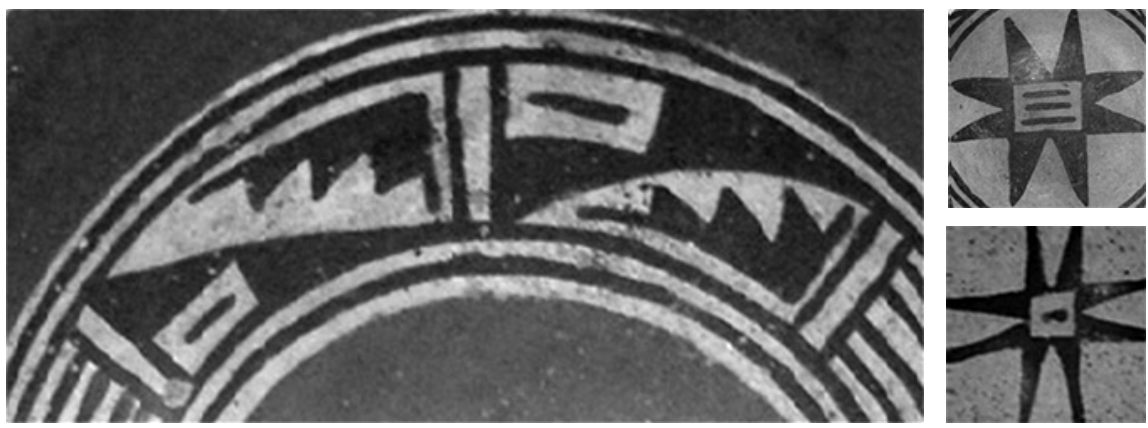

Figura 1. Diseño de la pieza 222 $\mathrm{A}^{3}$ - Tuza, ReCtángulo dividido en dos partes, y REPRESENTACIONES DEL SOL CON FORMA RECTANGULAR de LAS PIEZAS 191B y 212A - TuZa.

La figura de la escalera también aparece asociada con una línea espiral. Esta combinación está presente en los tres estilos, pero la forma de representación varía. En el estilo Capulí, el espiral nace de la parte posterior de la escalera, o en otros casos, el espiral se encuentra consecuentemente al punto donde termina la escalera (figura 2). En el estilo Piartal, la escalera más bien parece una línea ondulada o quebrada, y el espiral puede nacer de ésta, o encontrarse cerca (figura 3). En el estilo Tuza, en cambio, un rectángulo dividido en dos partes aloja en un lado la escalera y en el otro, el espiral, o la escalera puede estar contenida en un triángulo del cual nacen las líneas espirales (figura 4).
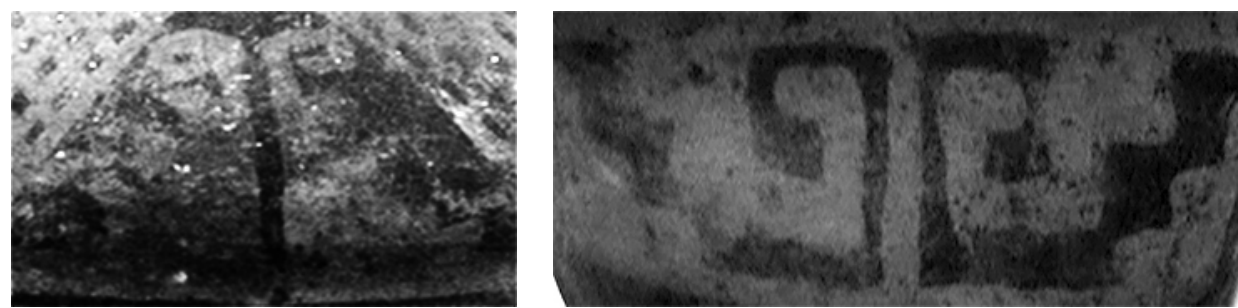

Figura 2. Diseño de la piezas 182A y 001A - Capulí, escalera más espiral.

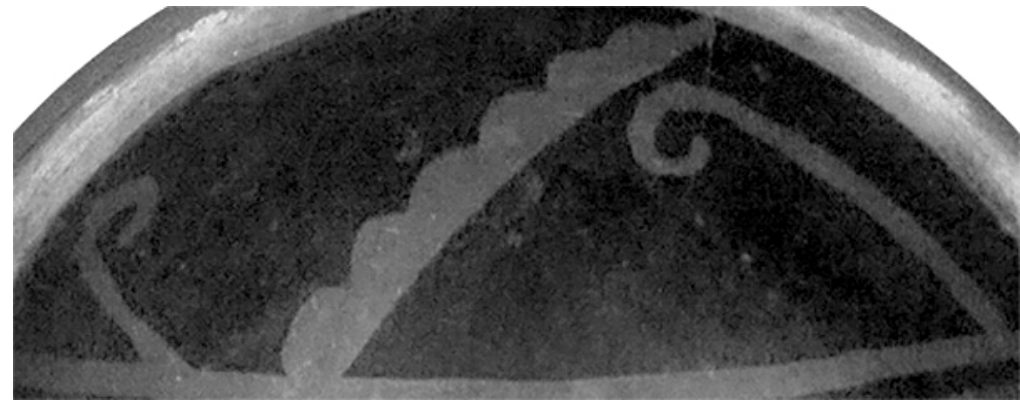

Figura 3. Diseño de la pieza 118A - Piartal, escalera más espiral.

3 Cada una de las piezas se identifica con un número secuencial seguido de la letra A o B, en donde A hace referencia a la colección del INPC y B, a la colección del Museo de BCE. 

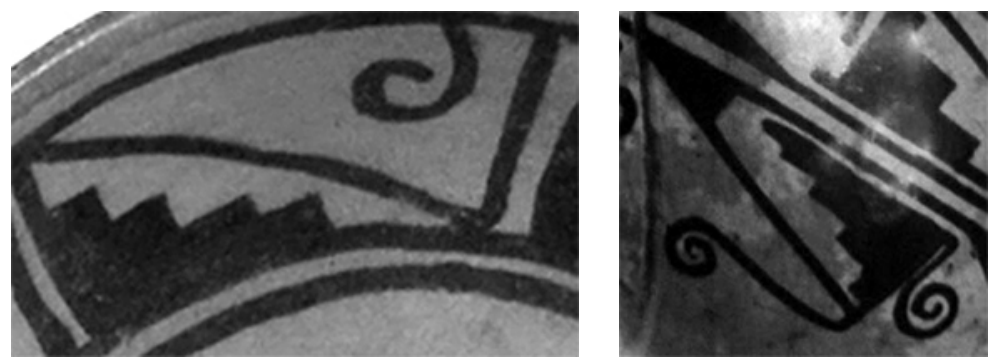

Figura 4: Diseño de la piezas 212A y 196B - TuZa, escalera más espiral.

Esta conjunción de elementos (escalera-espiral o escalera-ola), no sólo es particular en las decoraciones precolombinas de nuestro país, sino que también ha sido encontrada en las representaciones iconográficas de la cultura Moche, en Perú (figura 5). El diseño se ha interpretado como la dinámica entre elementos complementarios, que se pone de manifiesto mediante dos formas geométricas, una rectangular y una redondeada, que pueden evocar aspectos masculinos y femeninos (De Bock, 2003).
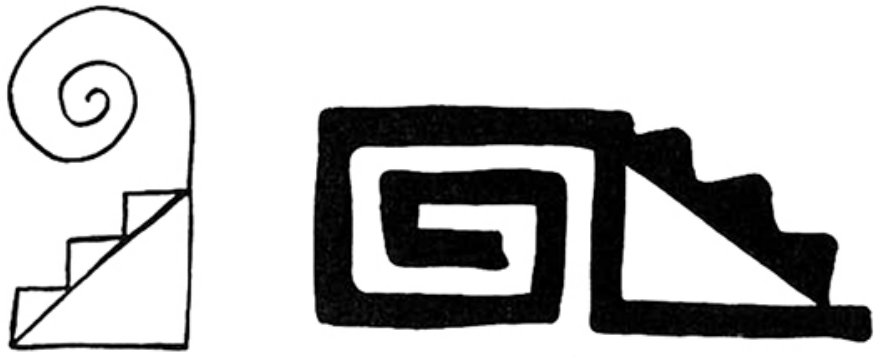

Figura 5. Diseño de la escalera más ola, cultura Moche (tomado de: De Bock 2003: 309).

El espiral además, aparece en conjugación con la figura de tipo B5.1 (dos triángulos unidos en sus puntas) (figura 6). Existen otras figuras en las que, sin necesidad de ser redondeadas, la idea de espiral está presente en el manejo de un mismo patrón geométrico, sea éste cuadrangular, triangular o romboidal (figura 7). Esta figura por tanto, parece tener una connotación simbólica muy importante, que se comprueba en la cantidad de diseños que se forman a partir de su uso.
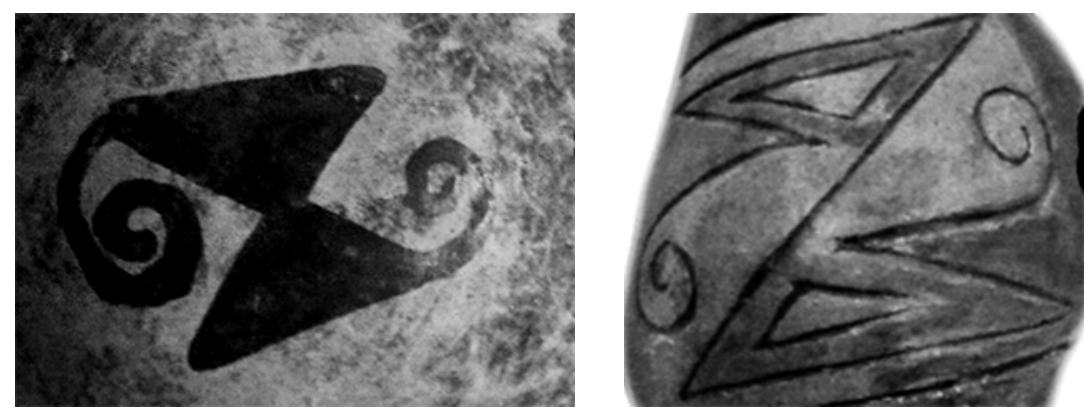

Figura 6. Diseños de la piezas 64B y 14B - TuZa. figura B5.1 más espirales. 


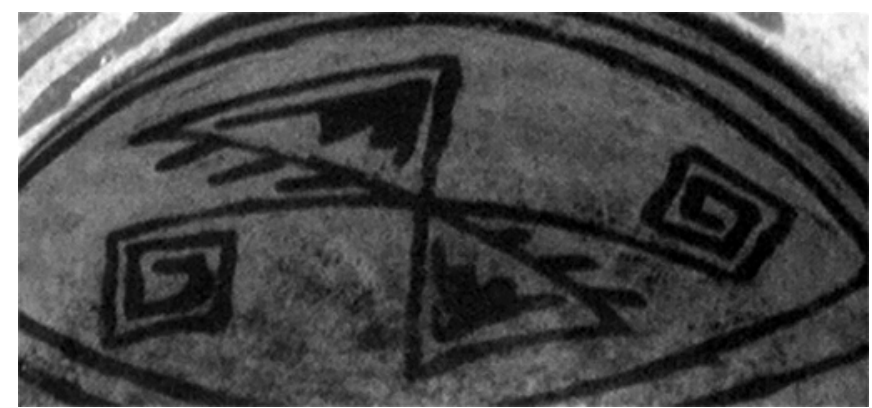

Figura 7. Diseños de la pieza 94B - Piartal, figura B5.1 más espirales.
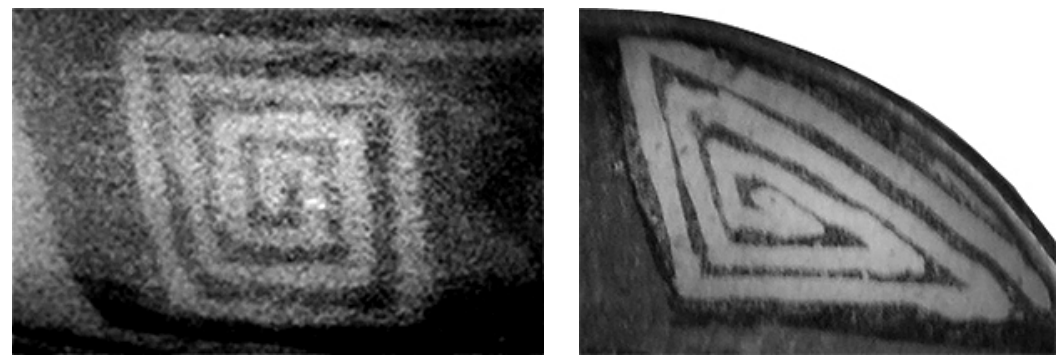

Figura 8: Diseños de las piezas 211B, Capulí, y 115B, Piartal, ESPIRALES CUADRANGULARES Y TRIANGULARES.

Del grupo de figuras con apariencia de sol, se ha encontrado que la mayoría de ellas están relacionadas con elementos lineales y geométricos, y existe también una significativa tendencia a aparecer asociadas a figuras con apariencia zoomorfa: monos, aves, felinos y venados, que, generalmente, se encuentran formando una línea alrededor de las mismas.

Con respecto a las figuras con apariencia zoomorfa, dentro de las cuales existen muchos animales que no corresponden al hábitat de esta región (lo cual sugiere una constante relación con culturas de la Costa y del Oriente), se han representado, en lo posible, lo más cercanas a la realidad. En nuestro corpus de imágenes, no existen representaciones de animales mitológicos, ni tampoco de animales antropomorfizados. Más bien la importancia parece radicar en el intercambio de especies, que son muy variadas de acuerdo a las figuras analizadas (venados, anfibios, tortugas, serpientes, lagartijas, arañas, felinos, osos, monos, aves, caracoles), no necesariamente para poseerlas de manera física, sino para apropiarse de ellas a través de las imágenes, que funcionarían como un sinónimo de las formas reales.

Gutiérrez (2009) explica que durante el período de Desarrollo Regional y de Integración, la fauna se encuentra estrechamente vinculada al poder. Esto se hace evidente al momento de fomentar una alimentación diferencial entre los grupos sociales y con la posesión de los medios de producción por parte de la élite, creando una lucha constante por mantener el control de las fuentes de proteínas. Es así como los caciques gozaban de privilegios sobre el aprovechamiento de la fauna, y sobre la posesión de amplios territorios de caza y recolección y de cazadores especializados. El común de la población no tenía acceso a la caza mayor, sin embargo la actividad de caza menor, servía para obtener especies que se tributaban a los caciques. Algunos productos animales, en forma de tejidos o de adornos, igualmente eran monopolizados para simbolizar prestigio. Otros, como patos y tórtolas, eran entregados como regalos para el establecimiento de relaciones. 
Dentro del material analizado, existe una mayor frecuencia en las representaciones de figuras zoomorfas con apariencia de mono. Éstos se manifiestan formando una línea alrededor de la pieza, pudiendo ser reflejo de sus costumbre gregarias (Gutiérrez, 2009), y uno frente a otro, cuando los diseños han sido divididos en partes iguales, haciendo referencia a nociones de dualidad (Ibid.). En cualquier forma de vasija cerámica, no aparecen representados solos, siempre están formando grupos o pares; a excepción de cuando han sido modelados sobre una ocarina, que en este caso, podría estar significando su complementario (fotografía 1).

Los monos son interpretados como mensajeros de los dioses, su presencia está asociada con los bosques y con rituales de invocación del viento y la lluvia, sobre todo al verse asociados con formas de caracoles marinos, los cuales siempre se han correspondido con contextos ceremoniales (Ibid.).

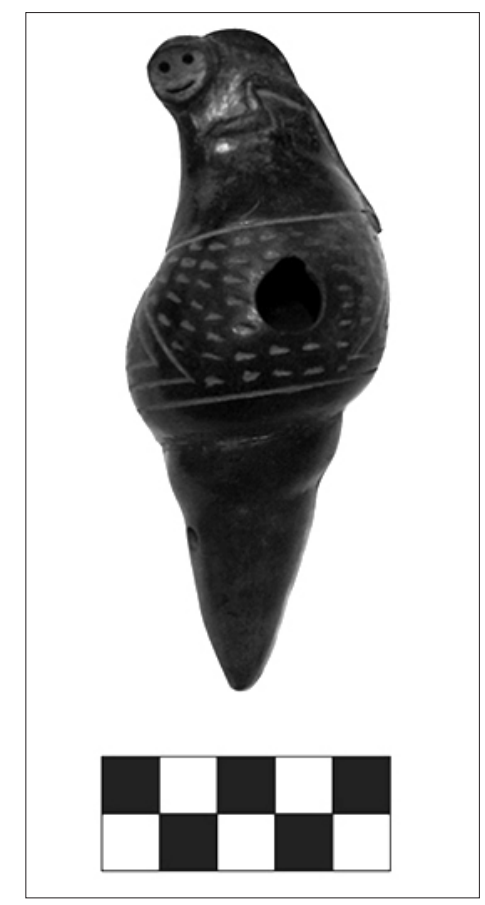

Fotografía 1. Pieza 147B - Piartal, mono modelado en ocarina

En cuanto al grupo de figuras con apariencia antropomorfa, podemos decir que, posiblemente estén evocando un sentido de jerarquización social, como lo sugieren también los datos arqueológicos de acuerdo al tipo de tumbas y ajuares encontrados. En el estilo Capulí, por ejemplo, solamente un tipo de personajes aparecen sentados en una especie de silla, masticando coca, vistiendo bandas y taparrabos, y a veces sosteniendo un pequeño recipiente en sus manos. Entre estos aspectos, llama la atención su vestimenta, si nos enfocamos en que se trata de sociedades, cuyos asentamientos principales han sido encontrados en territorios de climas fríos, y este tipo de vestimenta hace referencia a zonas de climas más cálidos. Por cuanto, posiblemente se trate de representar personajes de la misma sociedad que habitan en la parte más cálida, o personajes de culturas provenientes de la Costa o del Oriente.

De este tipo de personajes existe uno en particular, del cual hemos podido identificar, que el diseño perteneciente a la banda que cubre su cuerpo, se trata de la conjunción escalera más espiral, tratada en líneas anteriores, y que es exactamente el mismo diseño encontrado en una compotera cuadrangular de estilo Capulí. 

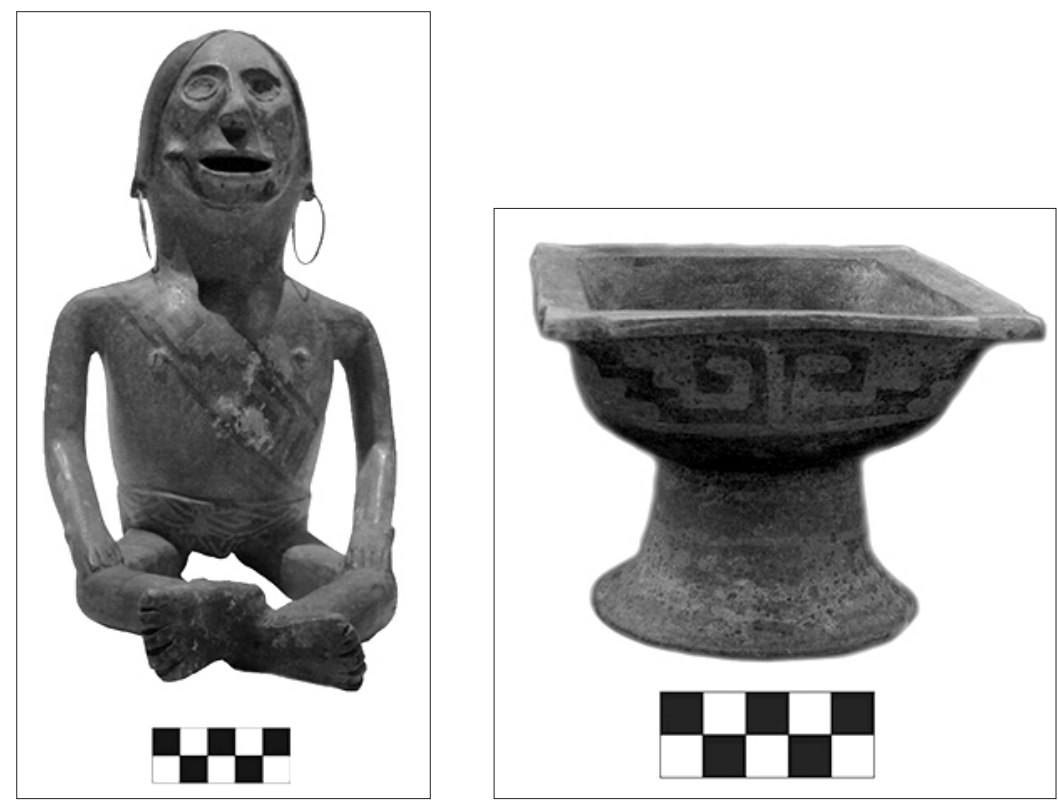

Fotografía 2. Piezas 202B y 001A - Capulí, figurina y compotera CON DISEÑO DE ESCALERA MÁS ESPIRAL.

En los estilos Piartal y Tuza, son pocos los personajes que visten elementos especiales, como tocados o bandas, éstos se caracterizan por la forma de sus caras que no son redondeadas sino cuadrangulares. Encontramos un personaje posiblemente de mucha importancia, pues lleva como tocado la forma del sol rectangular, y se representa solo, ocupando casi todo el interior de una compotera (fotografía 3); lo que no sucede comúnmente, pues en la mayoría de casos, aparecen personajes en parejas o conformando pequeñas agrupaciones.

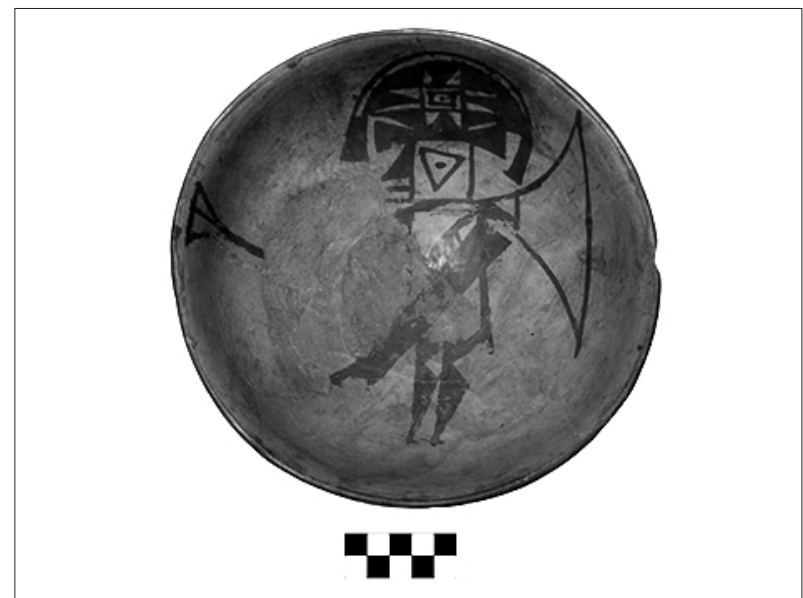

Fotografía 3. Pieza 193B, Tuza, figura con apariencia antropomorfa CON TOCADO DE SOL RECTANGULAR. 
Las figuras antropomorfas que no se han representado con ningún elemento distintivo, es común encontrarlas en grupos dispuestos alrededor del sol o de alguna otra figura, o en parejas, en los estilos Piartal y Tuza. En tres casos, aparecen además, asociadas a un ave, que posa su pico sobre sus cabezas (figura 9). Gutiérrez (2009) cree que se trata de un águila arpía. Lo que llama la atención con respecto a este tipo de conjunción, es que se ha hecho presente también en la cultura Moche, en donde un ave (cóndor) de gran tamaño, lleva en su pico una figura humana de pequeño tamaño, como si la estuviera ingiriendo (Benson, 2003) (figura 10).
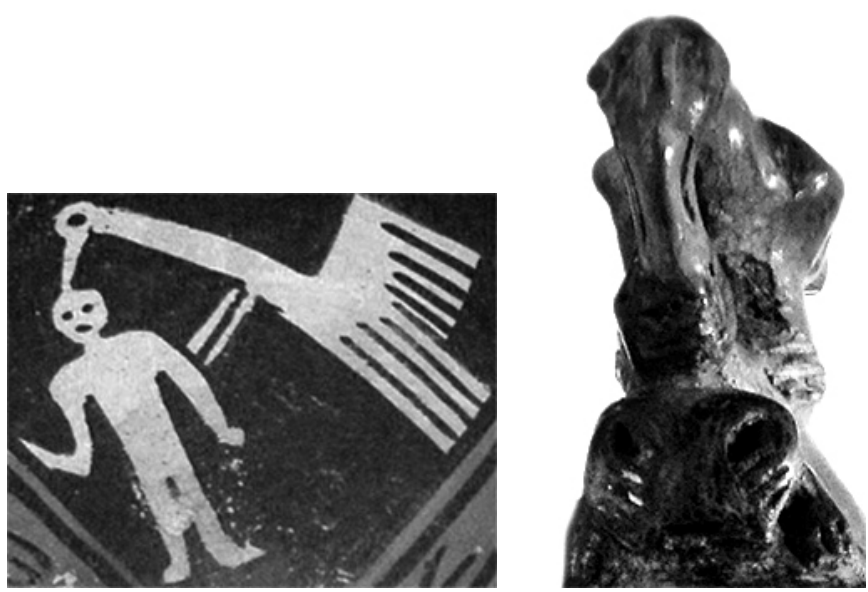

Figura 9. Diseño de la piezas 198A y 185B -Tuza, FIGURA ANTROPOMORFA RELACIONADA CON UN AVE.

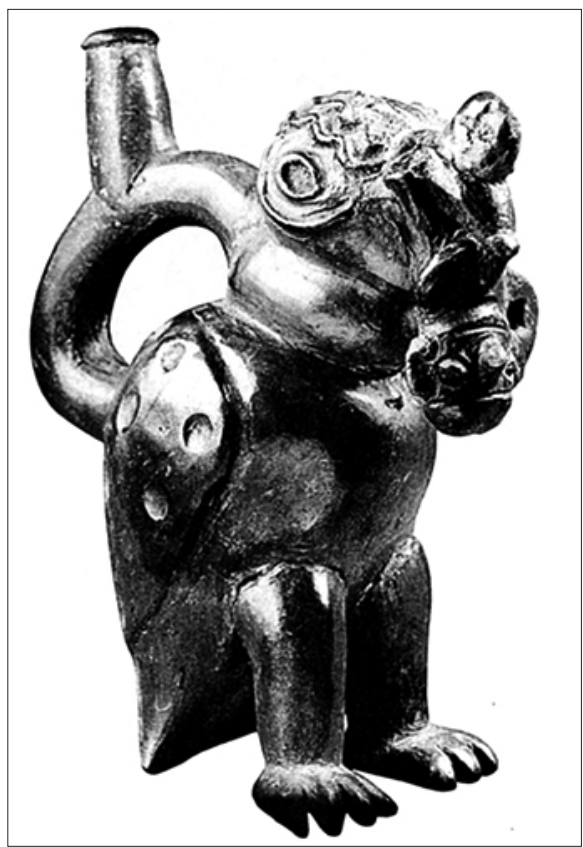

Figura 10. Figura antropomorfa Relacionada CON UN AVE, cultura Moche (Benson, 2003: 486). 
Es importante recalcar, además, que al menos, en nuestro material de análisis, no se han encontrado personajes antropomorfos en combinación con rasgos zoomorfos, es decir no hay representaciones de seres sobrenaturales. Lo que sí es común es que se esculpan rostros y a veces rostros con extremidades, en algunos tipos de vasijas (fotografía 4). Parecería ser que, si bien es cierto, no se encuentran figuras zoomorfas con rasgos antropomorfos, es más importante proporcionar estos rasgos a las vasijas.

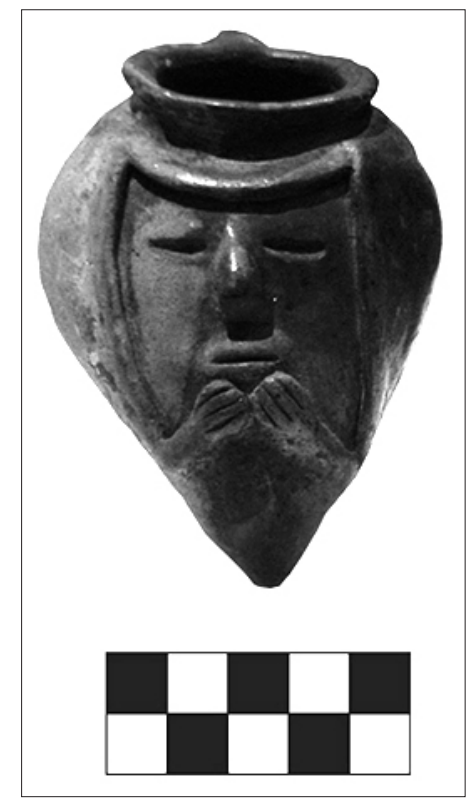

Fotografía 4. Pieza 187B - Piartal, representación de un rostro con extremidades.

\section{Generalidades en las formas de representación de las imágenes}

Existe una característica particular en las piezas, que es el hecho de dividirlas en una especie de paneles de representación; mediante líneas u otras formas se crean espacios iguales, los cuales albergan distintas figuras. Esta característica posiblemente evoque una idea de simetría, un sentido de orden en la concepción del mundo, que puede verse reflejado también en el hecho de intercalar figuras. Por ejemplo, al interior de las piezas, cuando se trata de tres paneles, el panel uno y el tres se corresponden de forma igualitaria y en este caso, el panel dos varía. Cuando se trata de cuatro paneles, el uno y el tres llevan las mismas representaciones, que son distintas a las representaciones del panel dos y cuatro (fotografía 5). En las piezas decoradas al exterior, se intercalan figuras geométricas con líneas que las van separando consecutivamente alrededor de la pieza.

Asimismo se puede hacer referencia a una de las características de las que habla Karadimas (2000), quien propone que se combinan elementos periféricos con elementos centrales. Lo cual es evidente en la mayoría de compoteras que se encuentran decoradas en el interior, ya que por lo regular encontramos una hilera de personajes zoomorfos, antropomorfos o geométricos, alrededor de un sol o de alguna otra figura (fotografía 6). Cárdenas (1998: 3) habla de que en el registro arqueológico, se han encontrado cementerios en los que se evidencia un personaje central, con ajuar y con cámaras más grandes y profundas, que los que se encuentran a su alrededor, y que mientras más se alejan del centro los entierros son menos profundos y con contenido 
menos elaborado; posiblemente esta tendencia se está reflejando también en las representaciones cerámicas.

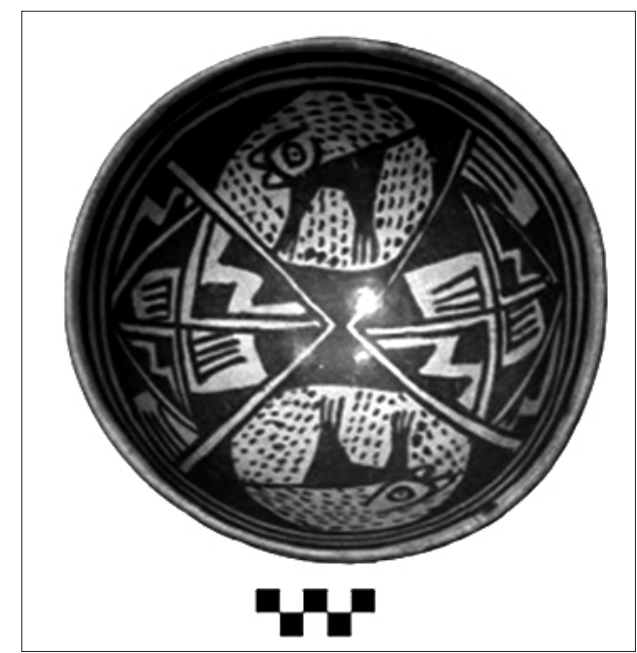

Fotografía 5. Pieza 190 B - Tuza, cuatro paneles de representación.

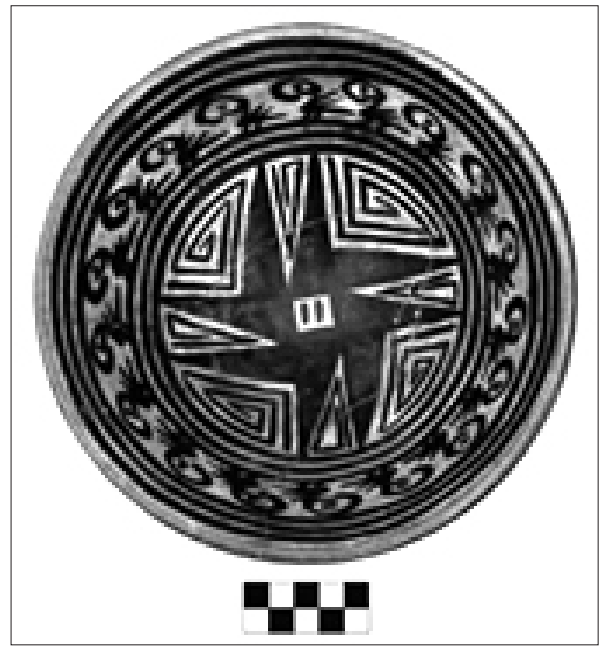

Fotografía 6. Pieza 51A - Tuza, figuras con forma de ave alrededor del sol rectangular.

Otra característica, es que para los diseños, se han empleado el uso de tres colores: el negro, el rojo (a veces también café oscuro) y el crema. Únicamente la cerámica del estilo Capulí utiliza dos colores: el negro sobre fondo rojo. Los estilos Piartal y Tuza utilizan dos o tres colores, es común el fondo crema, y cuando se usan tres colores, se intercalan figuras rojas con figuras negras. En los paneles de cuatro representaciones, las figuras con formas antropomorfas y zoomorfas, siempre están en color rojo.

Finalmente, vale la pena relacionar nuestras imágenes con las imágenes que se han reportado en los petroglifos y en el arte de la metalurgia de esta región. Generalmente en los petroglifos se han dibujado rectángulos, espirales, triángulos, líneas, círculos, estrellas, ranas, motivos antropomorfos, venados, monos, sol rectangular, etc. (figura 11). No existen estudios que hablen 
sobre el posible protagonismo de estos diseños, solamente se los ha asociado a la etnia Pasto por el territorio en donde se encuentran; sin embargo, en este trabajo hemos podido identificar las mismas figuras en la iconografía cerámica, sobre todo Piartal y Tuza (figura 12). En la metalurgia se han identificado diseños de monos, flores, aves, figuras geométricas, felinos, lagartos, caras humanas, escaleras, rombos, círculos, triángulos, rectángulos, medias lunas, espirales; que de la misma forma, se encuentran en nuestro material cerámico.

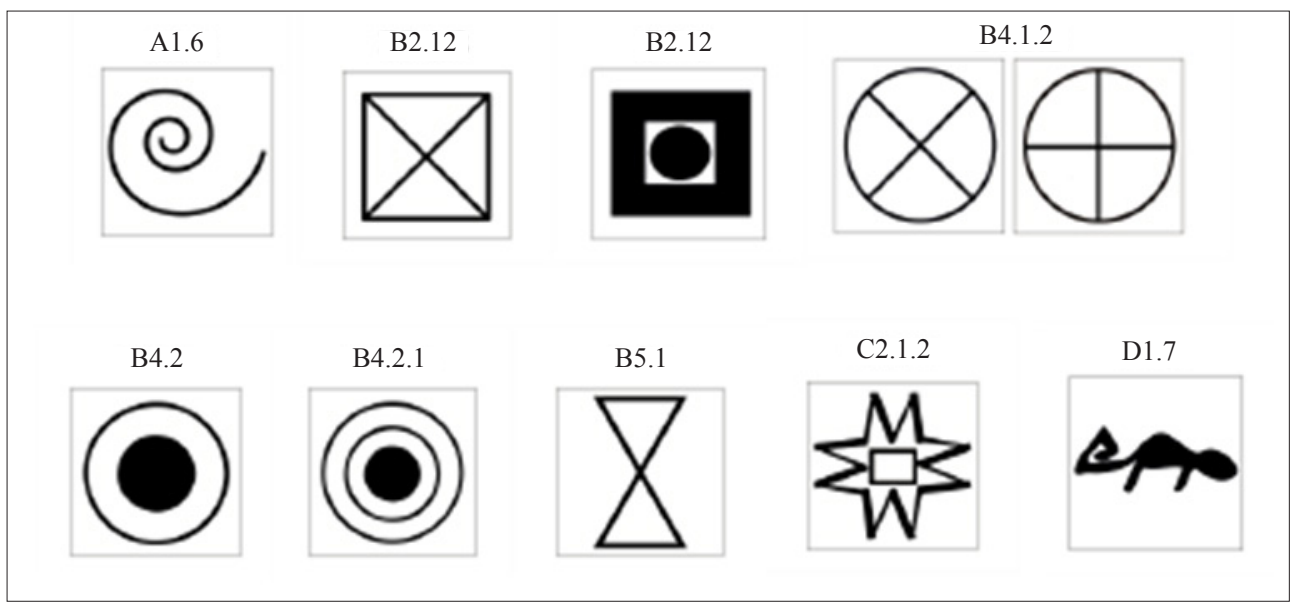

Figura 11. Diseños presentes en la COLECCión Cerámica.

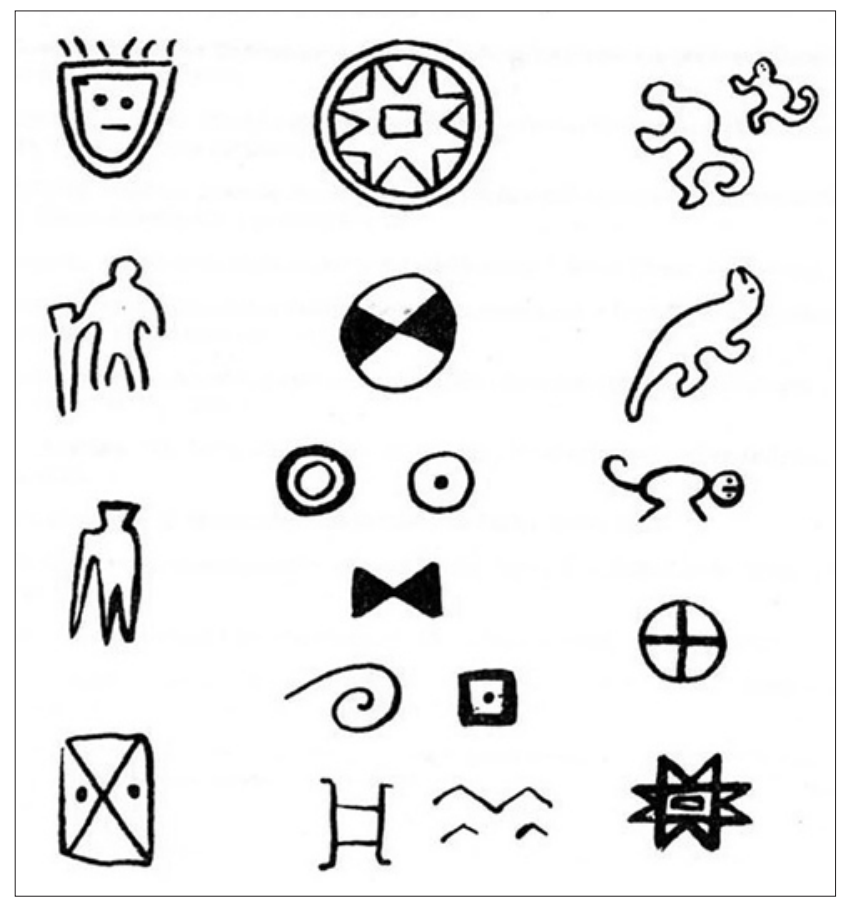

Figura 12. Diseños registrados en petroglifos (Granda, 1983: 31 ). 
Es posible que por la similitud en cuanto a la representación de estos diseños, se hable de que las mismas sociedades que produjeron la cerámica, hayan producido también los objetos de metal y hayan dejado huellas en cuanto al arte rupestre. Por lo tanto, nos encontramos frente a una sociedad que ha desarrollado su iconografía bajo diversos contextos, lo cual enfatiza la importancia que tuvieron los signos visuales dentro de la misma.

\section{Conclusiones}

Tras el análisis de las imágenes presentes en la iconografía de la cerámica del Carchi, se puede decir como primer punto que, aunque existen algunas figuras que son constantes en la mayoría de las piezas, sobre todo las figuras con apariencia lineal y las figuras con apariencia geométrica, en el material revisado, sí se pueden identificar diferencias enfocadas, principalmente, en las formas de utilización de las mismas y en la constancia con que son representadas.

En base a estas diferencias, se plantea que así como en algunos de los datos arqueológicos hasta ahora propuestos en cuanto a la cerámica, existe la evidencia de tres estilos, aunque esta diferencia es más clara respecto al estilo denominado Capulí, que se caracteriza por la utilización de dos colores, por una decoración externa de las piezas y por la representación de figuras antropomorfas y zoomorfas modeladas. Para la elaboración de sus diseños, son importantes las figuras con apariencia lineal y las figuras con apariencia geométrica, sobre todo las relacionadas con la forma de rombo, que es el estilo que las utiliza en mayor frecuencia.

En los estilos Piartal y Tuza, los diseños se realizan mediante la utilización de tres colores, se decoran tanto el interior como el exterior de las piezas y no existen figuras antropomorfas modeladas (más bien la representación de éstas se hace a través de la pintura), pero lo que sí se ha modelado son tres clases de caracoles. En Piartal, es muy típico el uso de figuras geométricas, lineales y figuras con apariencia de sol, específicamente para adornar las partes externas de las compoteras. En este estilo se han encontrado elementos que se podrían decir que son casi exclusivos para la formación de sus diseños, como son las líneas paralelas horizontales e inclinadas de igual o diferente tamaño, el uso de diferentes tipos de triángulos combinados en varias formas, la preferencia por una figura circular con un círculo pintado en su interior, el sol con apariencia redondeada y las figuras con forma de estrella.

En cuanto a la fase Tuza, es común representar figuras entrelazadas en forma lineal alrededor de las vasijas, tanto en el campo interno como en el externo. El exterior de las compoteras, regularmente no se decora con la combinación de figuras, como sucedía en Piartal, sino más bien con una banda de pintura que puede cubrir cualquier parte de la vasija. Las figuras con apariencia zoomorfa son mayormente usadas en esta fase, sobre todo los tipos con apariencia de ave, así como también la mayor parte de caracoles. Además, es común para la formación de sus diseños, las figuras con forma de cruz, con forma de escalera y con forma de "E". El sol con apariencia rectangular, aparece solo en esta fase, y respecto a las figuras con apariencia antropomorfa, se puede mencionar que se ha usado figuras geométricas para la elaboración de su cara, sus ojos y su cuerpo.

Como vemos existen diferencias que se han hecho evidentes a partir de la interrelación de las distintas figuras, pero no podemos dejar de lado aquellas que han sido relevantes en los tres estilos, como es la presentación de la escalera asociada con la línea espiral. Al parecer este motivo tuvo un fuerte simbolismo, marcado y aceptado durante mucho tiempo, lo que da la idea de que nos encontramos frente a un grupo social que se desarrolló bajo concepciones similares de ver y entender el mundo.

Segundo, considerando que las imágenes pueden comunicar ideas, expresando formas específicas de cómo un grupo humano vive y se reproduce en determinado ambiente y de cómo lo interpreta (Golte, 2008), hemos logrado reconstruir algunos datos que nos parecen pueden ser importantes. De forma general, como referentes para definir al mundo se hacen presentes ideas de centralidad en relación a elementos periféricos, de simetría y de un ordenamiento 
esquemático del espacio “... para entender una imagen de una cultura precolombina tenemos que comprender su cosmovisión y la forma como los miembros de esta cultura seleccionaban ciertos aspectos de ésta para comunicarla en imágenes" (Golte, 2008: 21).

De las figuras con apariencia zoomorfa encontramos que las representaciones, no obedecen en todas sus formas al medio ambiente de donde proviene el material cerámico, que aunque se caracteriza por poseer varios pisos altitudinales, se representan especies que provienen de la Costa y del Oriente, lo cual deja claro que hubo un constante contacto y comercio con diversas culturas, por medio del que se intercambiaron bienes de distinta índole. Lo que sí parece interesante es que además del intercambio material, al parecer también se intercambiaron símbolos: "En su función icónica los "bienes de élite" crearon en el suroccidente una comunalidad iconográfica que sobrepasó los límites sociales y políticos de los cacicazgos" (Genecco, 1995: 189); es por esto que encontramos figuras de monos, tortugas, lagartijas, serpientes, arañas, venados, caracoles, sapos, y una infinidad de aves adornando las vasijas. Estos animales no se encuentran con relación al contexto doméstico, y los animales que son considerados como parte del contexto doméstico, no están representados bajo ningún parámetro; por lo tanto, aunque no se puede afirmar que se trate de deidades, es posible que al menos están asociados con alguna actividad ritual.

Tercero, las imágenes por tanto, han sido consideradas como formas de producción de esta sociedad que ha trasmitido mediante éstas, un tipo de lenguaje. Como lo plantea Morales: “... todo lenguaje y en especial el andino, precolombino, explica de alguna manera la filosofía, religión, prácticas rituales y organización político espacial, así como las variables estilísticas locales o regionales" (2003: 433-434). Sin embargo, creemos firmemente que es viable y necesaria la lectura de muchos otros elementos ya que, la iconografía de esta región ha demostrado ser muy rica y con posibilidades de denotar características de esta sociedad que aún no han sido descubiertas.

\section{Bibliografía}

Barthes, Roland; Claude Bremond; Tzvetan Todorov y Christian Metz. 1972, La semiología, Tiempo Contemporáneo, Buenos Aires.

Bray, Tamara. 1998, Monos, monstruos y mitos conexiones ideológicas entre la sierra septentrional y el oriente del Ecuador, en: Cárdenas Felipe y Tamara Bray (eds.). Intercambio y comercio entre costa, andes y selva. Arqueología y etnohistoria de Suramérica. Universidad de los Andes, Bogotá, pp. 135-154.

Cárdenas, Felipe. 1995, "Complejos cerámicos como marcadores territoriales: el caso crítico de Piartal-Tuza en la arqueología de Nariño", en: Perspectivas regionales en la arqueología 165 del suroccidente de Colombia y norte de Ecuador, Universidad del Cauca, Popayán, pp. 49-58.

1996, "Frontera arqueológica vs. Frontera etnohistórica: Pastos y Quillacingas en la arqueología del Sur de Colombia", en: Frontera y poblamiento: estudios de historia y antropología de Colombia y Ecuador, Departamento de Antropología, Universidad de los Andes, Bogotá, pp. 41-56.

1998, La iconografía de la cerámica pintada del norte de los Andes. Centro cultural del BID, conferencia de Felipe Cárdenas Arroyo

Castañeiras, Manuel. 1998, Introducción al método iconográfico, Arial, Barcelona.

Cieza de León, Pedro. 1984, La crónica del Perú, Ediciones de Manuel Ballesteros, Madrid.

De Bock, Edward. 2003, "Templo de la escalera y ola y la hora del sacrificio humano", en: Uceda, Santiago y Elías Mujica (eds.). Moche hacia el final del Milenio, tomo I, Siklos, Lima, pp. 307-324.

Eco, Umberto. 1994, La estructura ausente, introducción a la Semiótica, Editorial Lumen, Barcelona.

Echeverría, José. 2004, Las sociedades prehispánicas de la sierra del norte del Ecuador. Una aproximación arqueológica y antropológica, Instituto Otavaleño de Antropología, Quito.

Eliade, Mircea. 1983, Imágenes y símbolos. Ensayos sobre el simbolismo mágico - religioso, Taurus Ediciones Madrid. 
Gnecco, Cristobal. 1995, "Relaciones de intercambio y bienes de élite entre los cacicazgos del Suroccidente de Colombia", en: Genecco, Cristóbal (ed.). Perspectivas regionales en la arqueología del Suroccidente de Colombia y Norte de Ecuador, Universidad del Cauca, Popayán, pp. 175-196.

Golte, Jürgen. 2008, "La modelación de una cosmología", (nueva versión), en; Scientia, Revista del Centro de Investigación de la Universidad Ricardo Palma 10 (10), pp. 17-36.

Granda, Osvaldo. 1983, Arte rupestre Quillasinga y Pasto, Sindamano, Pasto.

Groot, Ana y Eva Hooykaas. 1991, Intento de delimitación del territorio de los grupos étnicos Pastos y Quillacingas en el altiplano Nariñense, Fundación de investigaciones arqueológicas nacionales, Bogotá.

Gutiérrez Usillos, Andrés. 2009, Dioses, símbolos y alimentación en los Andes. Interrelación hombre - fauna en el Ecuador prehispánico, Abya - Yala, Quito.

Karadimas, Dimitri. 2000, "Monos y estrellas entre el Amazonas y los Andes, interpretación etnoarqueoastronómica de los monos del Carchi-Capulí (Colombia-Ecuador)", en: Amazonía peruana, tomo XIV, No. 27, pp. 145-192.

Landázuri, Cristobal. 1995, Los curacazgos pastos prehispánicos: agricultura y comercio, siglo XVI, Abya-Yala, Quito.

Martínez, Eduardo. 1977, Etnohistoria de los Pastos, Editorial Universitaria, Quito.

Molestina, María del Carmen. 1998, Transferencias ideológicas en la Sierra Norte (Ecuador), en: Guinea, Mercedes; Jorge Marcos y Jean Francois Bouchard (compiladores), El área septentrional Andina. Arqueología y Etnohistoria, Abya-Yala, Quito, pp. 223-241.

Morales, Ricardo. 2003, "Iconografía litúrgica y contexto arquitectónico en Huaca de la Luna, valle de Moche", en: Uceda, Santiago y Elías Mujica (eds.). Moche hacia el final del Milenio, tomo I, Siklos, Lima, pp. 425476.

Mithen, Steven. 1998, Arqueología de la mente, CRÍTICA (Grijalbo Mondadori, S.A.), Barcelona.

Panofsky, Erwin. 1970, El significado de las artes visuals, Ediciones Infinito, Buenos Aires.

Pearson, James. 2002, Shaminism and the ancient mind, a cognitive approach to archaeology, Altamira Press, USA.

Preucel, Robert. 2006, Archaeological semiotics, Blackwell Publishing, USA.

Renfrew, Colin y Cris Scarre. 1998, Cognition and Material Culture: the Archaeology of symbolic storage, McDonald Institute for Archaeologycal Researcher, USA.

Rob, John E. 1998, “The archaeology of symbols”, en: Annual Reviews, Annual Review of Anthropology, vol. 27, pp. 329-346.

Saussure, Fernandine. 2005. Curso de lingüistica general, LOSADA, Buenos Aires.

Valarezo, Galo. 2010, Carchi sorprendente, artesanía ancestral del Ecuador, Fundación Sinchi Sacha, Pueblos y Culturas de América, Ecuador. 
Anexo

\begin{tabular}{|c|c|c|}
\hline Categorías generales & Categorías específicas & Categorías interespecíficas \\
\hline & A1: Líneas simples & 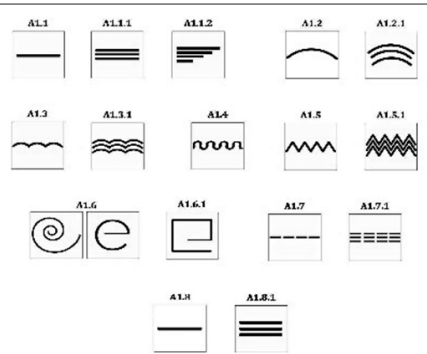 \\
\hline $\begin{array}{l}\text { A: Figuras } \\
\text { con apariencia lineal }\end{array}$ & A2: Líneas compuestas & 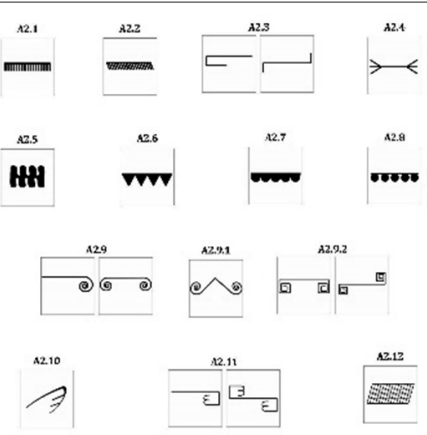 \\
\hline \multirow{2}{*}{$\begin{array}{l}\text { B: Figuras } \\
\text { con apariencia geométrica }\end{array}$} & B1: Con forma triangular & 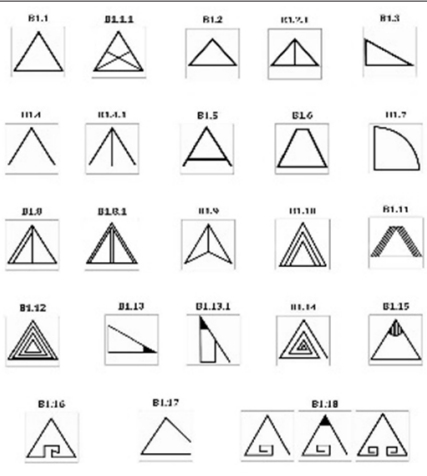 \\
\hline & $\begin{array}{l}\text { B2: Con forma } \\
\text { rectangular }\end{array}$ & 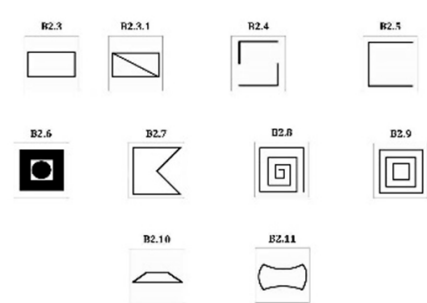 \\
\hline
\end{tabular}




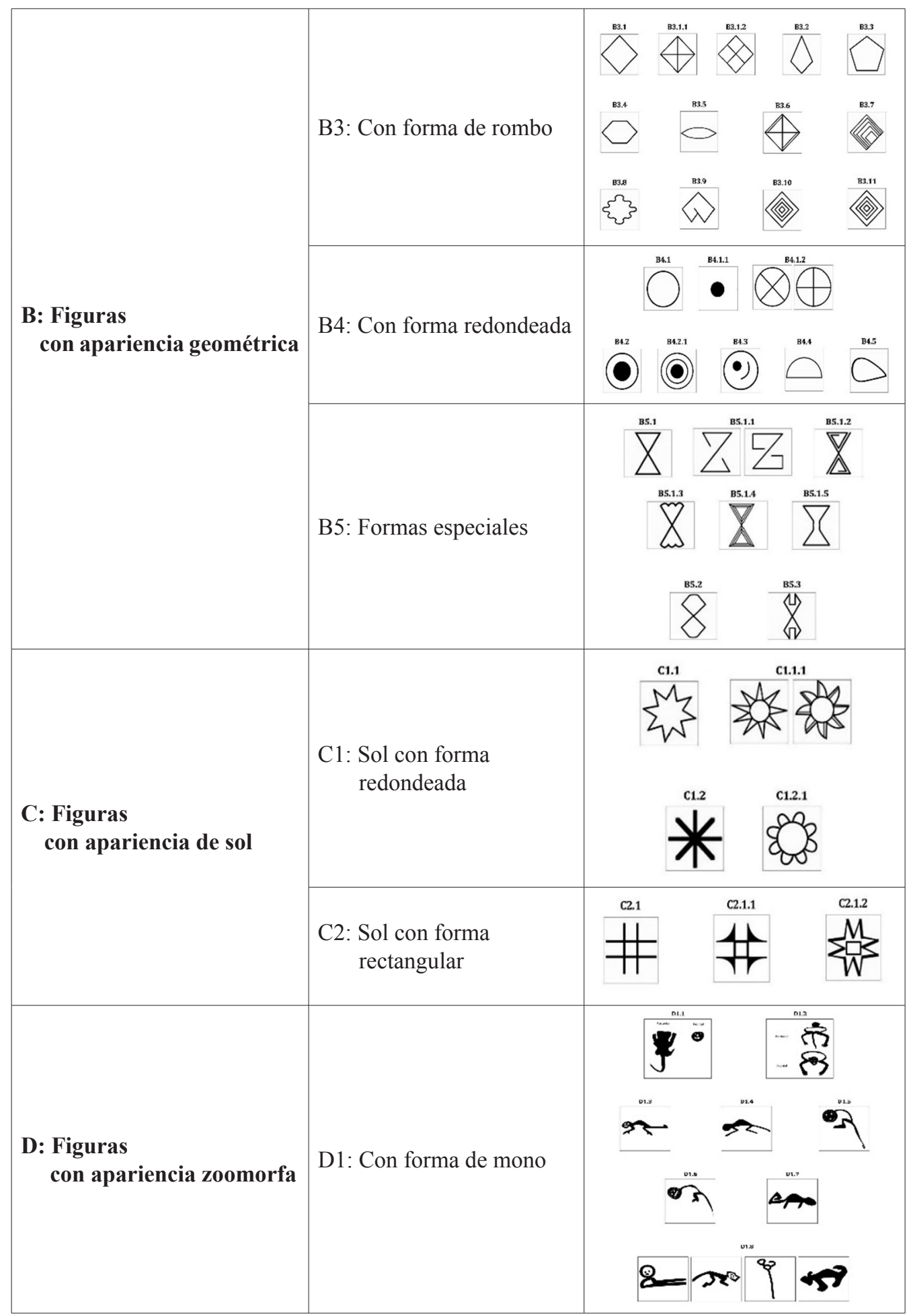




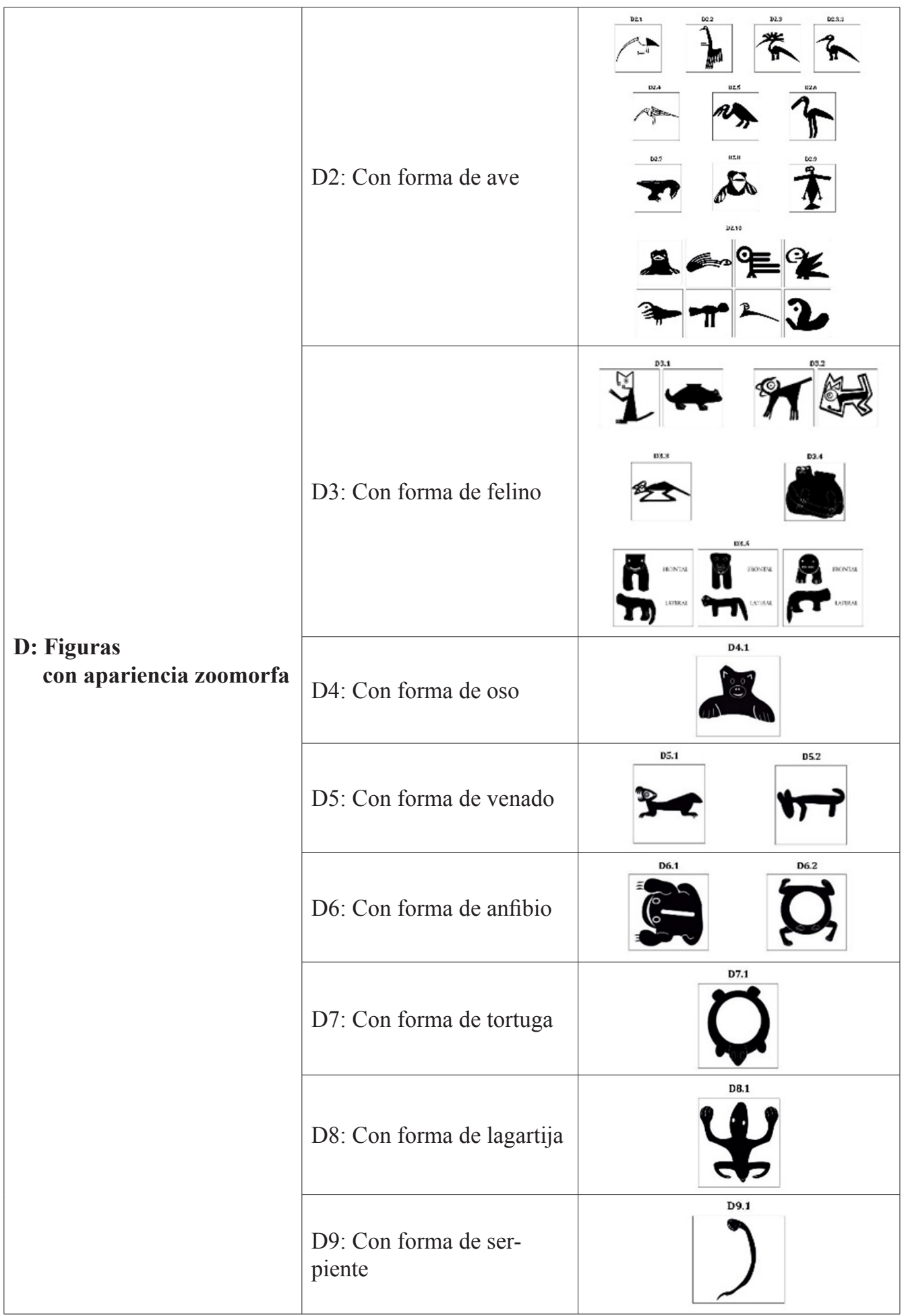




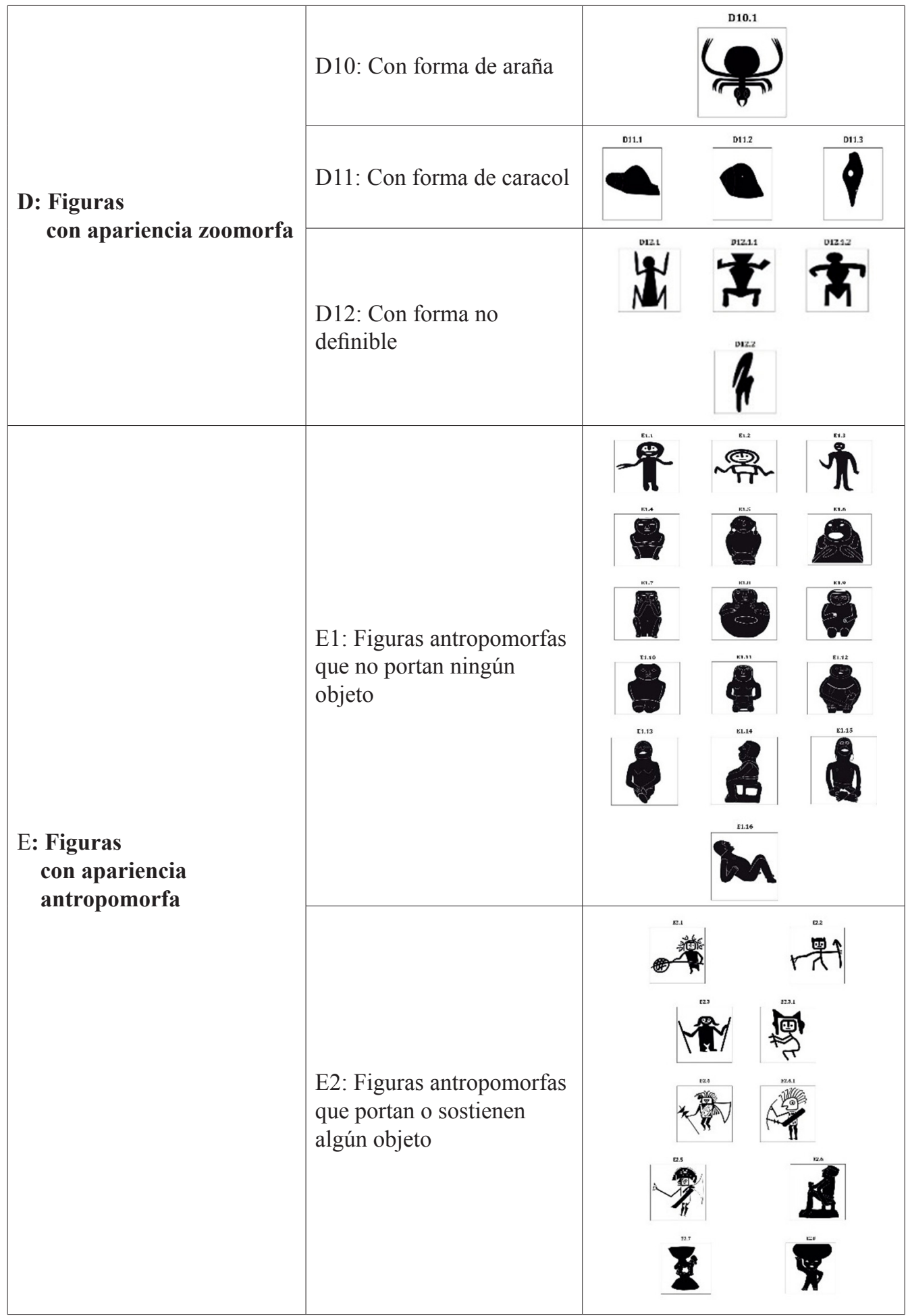




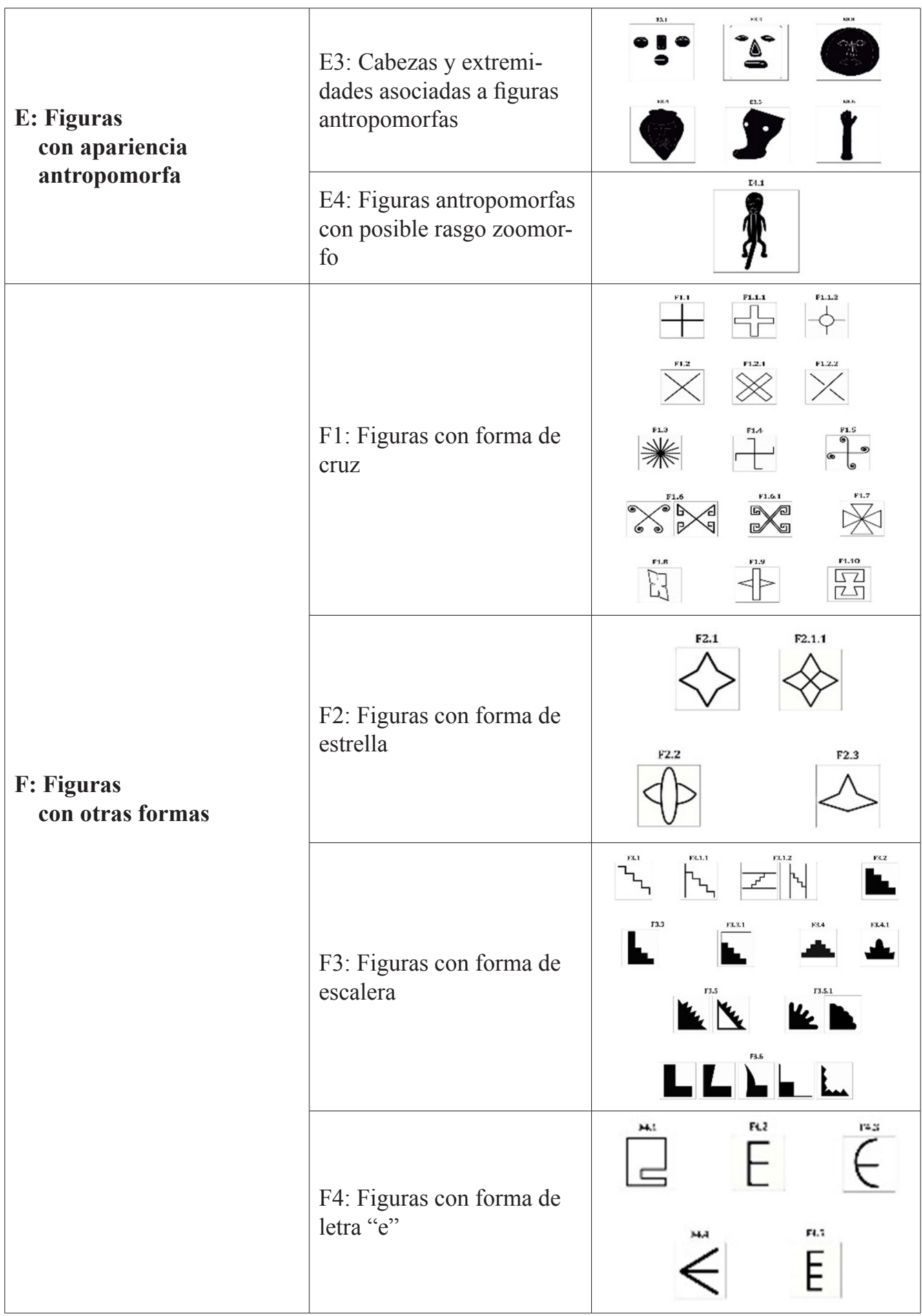


ANÁLISIS PRE-ICONOGRÁFICO DE LA CERÁMICA PRECOLOMBINA DEL CARCHI | 101

\begin{tabular}{|l|l|c|}
\hline \multirow{2}{*}{$\begin{array}{l}\text { F: Figuras } \\
\text { con otras formas }\end{array}$} & $\begin{array}{l}\text { F5: Figuras con forma de } \\
\text { rayo }\end{array}$ & $\begin{array}{l}\text { F6: Figuras con forma de } \\
\text { cuchara }\end{array}$ \\
\cline { 2 - 3 } &
\end{tabular}

